\title{
Perencanaan Pengembangan Destinasi Wisata Menggunakan Analisis MSP+DM
}

\author{
Setiawan Priatmoko \\ STIE Pariwisata API Yogyakarta \\ E-mail : eraynesance@gmail.com
}

\begin{abstract}
This methodology tools approach was conducted to design an analysis for the development of community-based tourism areas planning. The initial condition of an area needs to be determined first in a measurable quantitatively manner so that its development and goals can be established and more easily being evaluated. The variables used are elements in a tourism business activity, namely: Marketibility, Sustainability, Participatory, and Disaster Mitigation (MSP + DM). The conversion of several variables quantitatively becomes a value scale to measure of the attractions and tourism potential in the destination area.
\end{abstract}

Keywords: Community Based Tourism, Marketing, Sustainability, Participatory, Disaster Mitigation, $M S P+D M$

Abstrak - Penelitian ini dilakukan untuk merancang sebuah analisis untuk pengembangan kawasan wisata berbasis masyarakat. Kondisi awal sebuah kawasan perlu ditetapkan secara terukur agar pengembangan dan starteginya dapat ditetapkan dan lebih mudah dievaluasi. Variabel yang digunakan adalah unsur-unsur dalam sebuah aktifitas bisnis kepariwisataan yaitu: Kepemasaran/Marketibility, Keberlanjutan/Sustainibility, Parisipatif/Participatory, dan Mitigasi Bencana/Disaster Mitigation (MSP+DM). Pengkonversian beberapa variabel tersebut secara kuantitatif menjadi skala nilai untuk mengukur atraksi dan potensi wisata yang ada di kawasan pengembangan.

Kata Kunci : Pariwisata Berbasis Masyarakat, Kepemasaran, Keberlanjutan, Partisipatif, Mitigasi Bencana, MSP+DM

\subsection{Latar Belakang}

Pada umumnya konsep pengembangan pariwisata menggunakan metode SWOT (Strength, Weakness, Opportunities, dan Threat) yang biasanya dipakai oleh penelitipeneliti terdahulu. Analisis SWOT adalah salah satu jenis analisis yang paling umum digunakan dalam manajemen strategi (Goranczewski \& Puciato, 2010). Analisis SWOT didasarkan pada logika yang dapat memaksimalkan kekuatan (strengths) dan peluang (opportunities), namun secara bersaman dapat meminimalkan kelemahan (weakness) dan ancaman (threats) (Rangkuti, 2006). Namun untuk menganalisa sebuah kawasan wisata yang di dalamnya terkandung aneka kehidupan alam, sosial dan budaya, SWOT masih kurang efektif dalam menganalisa sebuah kajian perencanaan. Sebabnya selain karena kawasan tersebut terdapat perikehidupan masyarakat yang dinamis, SWOT akan menjadi sangat subyektif dan sulit dipertahankan konsistensinya ketika sebuah program pengembangan harus melewati fase-fase tertentu yang cepat berubah pada perkembangan sebuah kawasan wisata berbasis masyarakat. Pendekatan spontan dikarenakan situasi pasar yang berubah-ubah adalah situasi paling umum yang terjadi dalam pengembangan pariwisata dan produknya sehingga menimbulkan kekacauan pada hal-hal yang terkait aktifitas pariwisata pada suatu teritorial wilayah (Goranczewski \& Puciato, 2010). Selain itu SWOT sulit dipertahankan obyektifitasnya ketika ada pergantian personil yang melakukan analisa di lain kesempatan, baik dari pemerintah maupun dari masyarakat setempat. Hal lain yang lebih merisaukan adalah dalam bidang pariwisata saat ini apa yang dianggap kelemahan atau kekuatan belum tentu adalah sebuah kelemahan yang sesungguhnya. Fenomena tersebut sangat tergantung pada sikap dan kreatifitas pelaku wisata setempat dan juga target-target yang ingin dicapai. Kelemahan lain SWOT adalah penentuan dalam pengukuran dan evaluasi pada faktor-faktor strategis (Gao \& Peng, 2011). Sebagai contoh: di suatu kawasan wisata sulit mendapatkan bahan bakar gas untuk memasak, apakah ini akan dimasukkan pada kelemahan/ weakness, kekuatan/ strength, atau peluang/ opportunity? Beda analis akan menimbulkan persepektif yang bisa berbeda. Pada tataran kreatifitas, memasak dengan kayu adalah sebuah atraksi wisata yang unik dan otentik dibandingkan memasak dengan gas elpiji. Pada kondisi 
demikian, perdebatan akan menjadi panjang dan kontra produktif bagi sebuah rencana pengembangan kepariwisataan yang selalu dinamis. Dengan kata lain penggunaan SWOT sebagai perencanaan strategis untuk pengembangan destinasi dapat menjadi pekerjaan yang sulit karena banyaknya pilihan turunan strategi dari faktor-faktor lingkungan yang diukur (Oreski, 2012).

Saat ini pengembangan sektor pariwisata menjadi perhatian pemerintah Indonesia. Pariwisata telah diposisikan sebagai salah satu sektor utama yang diharapkan dapat meningkatkan pendapatan negara dan masyarakat. Pada kondisi tersebut, pemerintah daerah yang merasa memiliki potensi pariwisata berkepentingan untuk melakukan program pengembangan potensi tersebut sehingga menjadi penggerak ekonomi di daerahnya. Kawasan wisata berbasis masyarakat/ Comunity Based Tourism (CBT) menjadi andalan untuk mempercepat pertumbuhan dan pengembangan kawasan wisata. CBT biasanya digambarkan sebagai aktifitas pariwisata yang mengacu dalam melibatkan partisipasi masyarakat dan bertujuan untuk menghasilkan manfaat bagi warga lokal dengan memungkinkan wisatawan untuk mengunjungi komunitas ini dan belajar tentang budaya dan lingkungan (Garcia Lucchetti \& Font, 2013). Jenis pariwisata CBT tidak hanya merespon kebutuhan wisatawan, tetapi juga memberdayakan penduduk setempat untuk menerapkan pengetahuan mereka dalam mengelola pariwisata dalam komunitas mereka sendiri. Tujuannya adalah untuk melindungi dan memulihkan sumber daya alam agar seimbang dengan identitas lokal dan budaya serta untuk melayani perekonomian masyarakat (ASEAN, 2015). Pariwisata berbasis masyarakat juga berada pada lingkungan masyarakat, dimiliki oleh satu atau lebih anggota masyarakat setempat, dan dikelola oleh masyarakat temasuk dalam pengaruh dan pengelolaan usahanya (Zapata, Hall, Lindo, \& Vanderschaeghe, 2011). Secara tidak langsung mengembangkan kawasan CBT juga akan mendorong pertambahan kontribusi pendapatan bagi daerah.

\subsection{Identifikasi Masalah}

Berdasarkan uraian tersebut di atas, maka permasalahan yang akan di angkat dalam paparan ini adalah bagaimana alternatif metode analisis perencanaan pengembangan pariwisata berbasis masyarakat yang ideal khususnya menggunakan metode selain analisis SWOT.

\subsection{Fokus Dan Tujuan Studi}

Paradigma lama sering melihat aktifitas dan bisnis pariwisata lebih kepada sebuah produk. Ini tidak sepenuhnya salah. Memang secara garis besar produk lah yang akan selalu nampak pada sebuah aktifitas pemasaran/ marketing pariwisata dan bisnis turunannya. Namun dalam kaitan produk wisata yang berbasis masyarakat (CBT) ada hal-hal yang harus difokuskan yaitu:

Kepemasaran/ Marketibility, Keberlanjutan/ Sustainibility, dan Partisipasi masyarakat (Participatory). Ditambahkan pula dengan kondisi Kabupaten Bantul yang dianggap rawan bencana khususnya akibat aktifitas tektonik (gempa dan tsunami) serta bencana akibat faktor manusia maka diperlukan juga analisa mitigasi bencana/ Disaster Mitigation. Dari keempat fokus tersebut perlu dibuatkan sebuah alat / tools yang bisa membantu kepada pemerintah daerah dan masyarakat setempat untuk memberikan arahan pengembangan yang paling tepat. Hal lain yang tidak kalah penting ialah keempat komponen tersebut juga harus bisa dievaluasi dan bisa menjadi pijakan konsisten untuk rencana pengembangan pariwisata selanjutnya sekaligus sebagai fungsi kontrol/ monitoring atas apa yang sedang, sudah, dan akan dilanjutkan dalam tahun-tahun periode program yang berkesinambungan (multi years) (Purbadi, 2016).

\subsection{Tinjauan Pustaka}

\subsubsection{Konsep Kepemasaran (Marketibility)}

Pada dasarnya konsep kepemasaran adalah untuk menentukan apakah sesuatu yang dianggap sebagai produk wisata di sebuah kawasan mampu untuk dijual. Untuk itu hal-hal yang terkait dengan masalah produk dan pemasarannya adalah hal yang menjadi perhatian utama. Menurut Philip Kotler dan Amstrong (Kotler \& Amstrong, 2008) pemasaran/ marketing adalah sebagai suatu proses sosial dan managerial yang membuat individu dan kelompok memperoleh apa yang mereka butuhkan dan inginkan lewat penciptaan dan pertukaran timbal balik produk dan nilai dengan orang lain. Dalam pertukaran timbal balik tersebut tentulah yang akan menjadi acuan bersama salah satunya adalah harga. Menurut Guiltinan dan Paul (1992) definisi strategi pemasaran adalah pernyataan pokok tentang dampak yang diharapkan akan dicapai dalam hal permintaan pada target pasar yang ditentukan. Menurut (Huwae, 2008) pemasaran destinasi memperhatikan kebijakan produk dengan memperhatikan unsur atraksi, amenitas, dan aksesibilitas juga penetapan 
segmentasi pasar, target dan upaya memposisikan potensi pariwisata. Menurut Kotler (2001) Perusahaan yang cerdas dalam hal pemasaran menggunakan media yang terarah dan mengintegrasikan komunikasi pemasaran mereka untuk mengirim pesanpesan yang konsisten melalui setiap pelanggan. Berbagai konsep diatas pada akhirnya berpadu dalam sebuah aktifitas yang disebut kepemasaran/ marketibility yaitu suatu keadaan bagaimana suatu hal dapat terjual sesuai yang ditargetkan. Dalam bidang pariwisata maka yang akan menjadi acuan variabel Kepemasaran adalah:

1. Penentuan Pasar yaitu akan menyasar siapa. Saat ini Mass tourism/ pariwisata masal tetap masih menjadi menopang banyak pelaku pariwisata secara umum di Indonesia

2. Produk yaitu keunikan dan orisinilitas khas daerah setempat yang dianggap sebagai sebuah atraksi wisata

3. Harga yaitu kesepakatan atas margin keuntungan yang ingin diperoleh dan pembagiannya di antara para pelaku bisnis pariwisata

4. Distribusi yaitu kestabilan ketersediaan aneka produk wisata dan penyampaian kepada konsumen/ wisatawan

5. Promosi yaitu komunikasi penyebaran informasi atas rangkaian produk-produk wisata daerah setempat

\subsubsection{Konsep keberlanjutan (sustainability)}

Dengan berkembangnya aktifitas pariwisata yang nyata-nyata mempengaruhi lingkungan, maka hal yang terkait keberlanjutan / sustainibility menjadi isu yang tidak terelakkan. UNWTO juga menunjukkan bahwa investasi yang berorientasi keberlanjutan (green investment/ Sustainibility tourism) di bidang pariwisata dapat berkontribusi untuk menumbuhkan perekonomian, penciptaan pekerjaan yang layak dan pengentasan kemiskinan sambil meningkatkan efisiensi sumber daya dan meminimalkan degradasi lingkungan (UNEP, 2011). Secara lebih tegas pariwisata berkelanjutan menjelaskan kebijakan, praktik dan program yang memperhitungkan tidak hanya harapan wisatawan tentang tanggung jawab pengelolaan sumber daya alam, tetapi juga kebutuhan di pihak masyarakat penyedia layanan pariwisata yang mendukung atau dipengaruhi oleh proyek pariwisata dan lingkungannya (UNEP, 2011). Dengan kata lain masyarakat dan lingkungan setempat yang berada dalam lingkungan aktifitas pariwisata harus diperhatikan dan menjadi bagian dari analisis pengembangan sebuah kawasan.

Dalam kondisi demikian maka Variabelvariabel yang terkait dengan isu-isu lingkungan alam (nature) maupun lingkungan bisnis menjadi penting seiring dengan kesadaran akan dampak negatif dari aktifitas wisata. Pariwisata berkelanjutan sendiri menurut UNWTO, UN Environmental Programme (UNEP), dan UN Foundation and the Rainforest Alliance pada tahun 2008, harus memiliki tujuan :

1. Keuntungan maksimal untuk masyarakat lokal

2. mengurangi dampak negatif pada budaya asli setempat

3. mengurangi dampak yang merusak pada lingkungan alam

4. Adanya perencanaan untuk keberlanjutan (UNWTO, 2011).

sehingga analisa prinsip keberlanjutan (sustainibility) harus digunakan. Sustainibility prinsipnya adalah memenuhi kebutuhan sekarang tanpa mengorbankan pemenuhan kebutuhan generasi masa depan. Untuk itu yang diperhatikan dalam hal ini adalah :

1. Daya dukung tiap produk-produk wisata

2. Pengolahan limbah

3. Pemeliharaan lingkungan hidup

4. Kunjungan wisatawan yang berlanjut

5. Pengembangan bisnis pelaku dan kelompok terkait

Kelima hal di atas cukup menunjukkan keterwakilan yang holistik akan makna sebuah kegiatan pariwisata yang berkelanjutan.

\subsubsection{Konsep Partisipatif (Participatory)}

Hal menarik lainnya adalah kini aktifitas pariwisata menjadi aktifitas bisnis yang lebih membumi dan melibatkan banyak masyarakat setempat. Trend Pariwisata Berbasis Masyarakat (CBT/ Community Base Tourism) dan partisipasinya muncul di berbagai khasanah peraturan mulai dari UNWTO sampai pada tingkat peraturan daerah setempat bahkan pada tataran gugus masyarakat terkecil semacam dusun atau pedukuhan. Untuk itu sangat diperlukan ukuran partisipatif dalam variabel sebuah perencanaan pariwisata. Dalam analisa partisipatif digunakan teori Community-Based Resorces Management oleh Korten (1986) dan Pitana (1999) dalam Arismayanti (Arismayanti, 2010) dengan memperhatikan hal-hal sebagai berikut :

1. Penguasaan Sumber daya lokal/ local resources oleh masyarakat setempat

2. Tanggung Jawab Lokal/ local accountability

3. Kevariasian antar daerah / local variety 
Digunakannya ketiga hal di atas tidak dapat dipungkiri lagi akan mencerminkan kepentingan kuat masyarakat dalam kaitannya peran serta mereka dalam aktifitas kepariwisataan khususnya pariwisata berbasis masyarakat $(C B T)$.

\subsubsection{Konsep Manajemen Mitigasi Bencana (Disaster Mitigation)}

Menurut PBB arti bencana adalah Sebuah gangguan serius dari berfungsinya suatu

komunitas atau masyarakat yang melibatkan dampak secara luas manusia, material, ekonomi atau dampak kerugian lingkungan, yang melebihi kemampuan

komunitas atau masyarakat yang terkena dampak untuk mengatasi menggunakan sumber daya mereka sendiri (UNISDR, 2009). Menurut UU RI Nomor 24 Tahun 2007, mengatakan bahwa pengertian mitigasi dapat didefinisikan. Pengertian mitigasi adalah serangkaian_upaya untuk mengurangi resiko bencana, baik melalui pembangunan fisik maupun penyadaran dan peningkatan kemampuan menghadapi ancaman bencana (Republik, 2007). Mitigasi berupaya mencegah peristiwa yang membahayakan dan bila memungkinkan, mengurangi keparahan ketika

terjadi, dan meminimalkan kerugian dan kerusakan berikutnya (Miller, Engemann, Yage, \& Yager, 2006). Menurut Undangundang Nomor 24 Tahun 2007 Tentang Penanggulangan Bencana, dikelompokkan dua jenis bencana yaitu:

1. bencana alam dalam hal ditentukan dari kondisi dan histori bencana kawasan yang akan dikembangkan misalnya pernah terjadi gempa dan atau tsunami

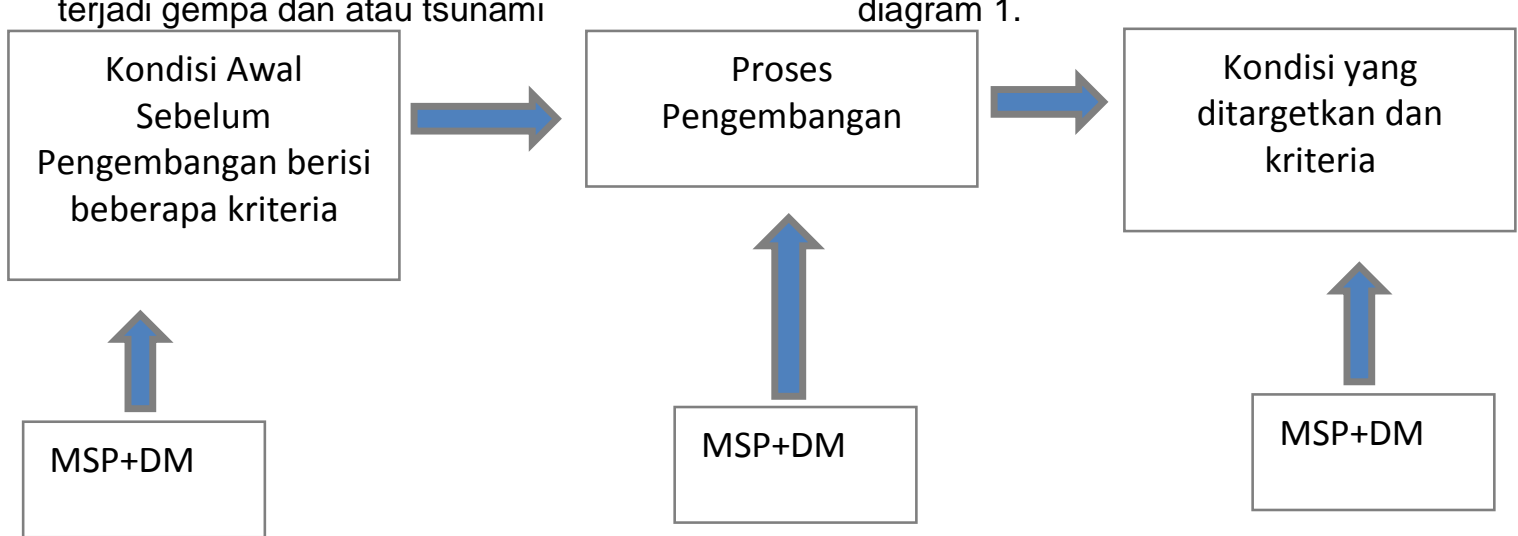

Gambar 1. Diagram Peran MSP+DM pada tahapan kondisi (Priatmoko, 2018)

\subsection{Metode Penelitian}

Metode analisis yang digunakan dalam penelitian ini analisis deskriptif kuantitatif. Analisis deskriptif dan kuantitatif ini meliputi
2. bencana non alam khususnya untuk penanganan resiko-resiko yang mungkin timbul atas produk-produk wisata yang ada di kawasan

Berangkat dari dua jenis bencana tersebut maka diperlukan analisis yang terkait agar aktifitas pariwisata menjadi lebih dapat termitigasi sejak awal untuk mengurangi resiko yang lebih besar bagi wisatawan maupun pengelola setempat.

\subsubsection{Konsep Cara Kerja MSP+DM}

Variabel-variabel analisis yang yang digunakan dalam pengembangan pariwisata menggunakan aspek Marketing, Sustainability, Participatory sehingga analisis tersebut dinamakan analisis MSP+DM. DM adalah kependekan dari Disaster Management (Manajemen mitigasi bencana). MSP+DM dirancang secara khusus sebagai Instrumen pengukuran awal untuk mengetahui kondisi awal kawasan pengembangan. MSP+DM juga digunakan untuk strategi pengembangan jangka panjang dan monitoring serta evaluasi pelaksanaan pengembangannya. Konsepkonsep yang MSP+DM dianggap relevan dengan program pengembangan kawasan wisata (Purbadi, 2016).Bagan di bawah ini menjelaskan MSP+DM menjadi instrumen pada tahap awal, di setiap tahap tahun pengembangan, dan pada tahap yang ditargetkan, sehingga status dan progres pengembangan dapat dipahamai secara rasional, obyektif, dan parametrik. Artinya, $\mathrm{MSP}+\mathrm{DM}$ dapat menjadi instrumen pengukuran kondisi awal serta menjadi dasar pengembangan secara bertahap khas pengembangan kawasan wisata dan berkelanjutan (multi years) seperti terlihat pada diagram 1

atraksi, potensi pasar, kelembagaan, profil kawasan, dan profil wisatawan.

1. Analisis atraksi menggunakan parameter kuantitatif MSP+DM 
Dalam analisis MSP+DM terlebih dahulu ditetapkan dan dipilih atraksi yang sudah ada (existing) dan potensi atraksi yang akan diungkap dalam waktu dekat (atraksi potensial). Aneka atraksi tersebut tersebut kemudian ditetapkan untuk dinilai dalam parameter-parameter yang diturunkan dari variabel-variabel yang terdapat dalam aspek Kepemasaran (Marketibility), Keberlanjutan (Sustainibility), Partisipatif (Participatory), dan Mitigasi Bencana (Disaster Management). Parameterparamater tersebut selanjutnya diberi skala nilai (scaling) yaitu instrumen yang mengaitkan konstruksi kualitatif dengan satuan metrik kuantitatif. Tujuan scaling ini adalah untuk memudahkan penilaian akan setiap aspek dan memberikan

Tabel 1. Tabel Penilaian dan Indikator MSP+DM (S. Priatmoko, 2018)

\begin{tabular}{|l|l|l|l|l|l|l|}
\hline Parameter & Rincian Unsur & Nilai 1 & Nilai 2 & Nilai 3 & Nilai 4 & Nilai 5 \\
\hline MSP+ DM & $\begin{array}{l}\text { Unsur-unsur } \\
\text { MSP+ DM }\end{array}$ & Indikator & Indikator & Indikator & Indikator & Indikator \\
\hline & Embrio & & \\
\hline
\end{tabular}

Dari total rata-rata nilai yang diperoleh selanjutnya akan ditetapkan kriteria kondisi awal sebuah kawasan pengembangan untuk ditentukan programnya yang targetnya menaikkan skor kriteria kawasan tersebut. Adapun kriteria-kriterianya dibagi menjadi beberapa berdasarkan nilai skor yang diperoleh. Kriteria tersebut diurutkan dari nilai terendah ke yang tertinggi adalah: Embrio, Rintisan, Tumbuh, dan Mandiri. Suatu kawasan pengembangan pariwisata dianggap pada kondisi yang dianggap paling ideal dan menjadi target akhir adalah dalam kriteria Mandiri (lihat tabel 2). konsistensi persamaan persepsi bagi semua pihak dan di waktu mendatang.

2. Penggunaan skala nilai dianggap bisa sangat mengurangi subyektifitas masingmasing peneliti/analis atau pihak terkait agar mendapatkan gambaran yang mendekati obyektif meskipun terjadi pergantian personil. Aspek yang dianggap lemah kondisinya akan diberi nilai rendah dan yang aspek yang dianggap kuat diberi nilai tinggi dengan parameter nilai 1 (terendah) sd nilai 5 (tertinggi). Pergeseran nilai dari nilai rendah ke nilai yang lebih tinggi menunjukkan posisi kriteria yang akan dicapai untuk program pengembangan yang disasar. Tabel penilaian dapat dicermati sebagai berikut:

\subsection{Jenis Dan Sumber Data Yang Dipergunakan}

\subsubsection{Data Primer}

Data primer merupakan data yang diperoleh secara langsung dari sumber pertama, dimana dalam penelitian ini diperoleh melalui pengamatan lingkungan dan wawancara mendalam serta kelompok diskusi terfokus/ Focus Group Discussion (FGD) yang melibatkan beberapa elemen dalam pengelolaan kawasan tersebut.

\subsubsection{Data Sekunder}

Data sekunder dalam penelitian ini didapatkan bukan secara langsung (terlebih dahulu diolah dan diteliti oleh peneliti lain atau sumber lain) yaitu :

1. Data Internal pengelola kawasan wisata 
2. Data mengenai parameter yang sudah dikonversi menggunakan skala dalam kelompok-kelompok MSP+DM.

\subsection{Hasil Dan Pembahasan}

Setelah didapat hasil pengumpulan data atraksi dan potensi wisata di sebuah kawasan yang akan dikembangkan semua atraksi dan potensinya dipetakan dan didata selanjutnya disiapkan tabel penilaian dan indikator

Tabel 2. Isi Skala Parameter dan unsur penilaian MSP+DM (Setiawan Priatmoko, 2018)

\begin{tabular}{|c|c|c|c|c|c|c|}
\hline \multicolumn{7}{|c|}{ 1. PEMASARAN (MARKETIBILITY) } \\
\hline \multirow{2}{*}{ PARAMETER } & \multirow{2}{*}{ RINCIAN UNSUR } & \multicolumn{5}{|c|}{ NILAI DAN INDIKATORNYA } \\
\hline & & Nilai 1 & $\begin{array}{c}\text { Nilai } 2 \\
\end{array}$ & $\begin{array}{c}\text { Nilai } 3 \\
\end{array}$ & Nilai 4 & Nilai 5 \\
\hline $\begin{array}{l}\text { A. Pengema } \\
\text { san Produk } \\
\text { Wisata }\end{array}$ & $\begin{array}{l}\text { Bentuk kemasan barang } \\
\text { ataupun jasa-jasa wisata } \\
\text { yang ditampilkan }\end{array}$ & $\begin{array}{l}\text { Bila belum ada } \\
\text { kesepakatan } \\
\text { bentuk dan } \\
\text { tampilan aneka } \\
\text { jenis produk wisata }\end{array}$ & $\begin{array}{l}\text { Bila sudah ada pelaku } \\
\text { yang membuat } \\
\text { standar untuk } \\
\text { tampilan aneka jenis } \\
\text { produk wisata, namun } \\
\text { belum untuk semua } \\
\text { produknya }\end{array}$ & $\begin{array}{l}\text { Bila sudah ada } \\
\text { standarisasi tampilan } \\
\text { jenis produk, namun } \\
\text { untuk jenis usaha } \\
\text { tertentu }\end{array}$ & $\begin{array}{l}\text { Bila sudah ada } \\
\text { kesepakatan dan } \\
\text { standarisasi bentuk } \\
\text { dan semua jenis } \\
\text { produk wisata }\end{array}$ & $\begin{array}{l}\text { Bila sudah ada } \\
\text { kesepakatan dan } \\
\text { standarisasi bentuk } \\
\text { dan semua jenis } \\
\text { produk wisata dan } \\
\text { kesinambungan } \\
\text { tematik }\end{array}$ \\
\hline $\begin{array}{l}\text { B. Model } \\
\text { Promosi }\end{array}$ & $\begin{array}{l}\text { Pilihan berbagai media } \\
\text { promosi }\end{array}$ & $\begin{array}{l}\text { Bila belum } \\
\text { menggunakan } \\
\text { aneka model } \\
\text { promosi }\end{array}$ & $\begin{array}{l}\text { Bila sudah ada pelaku } \\
\text { yang menggunakan } 1 \\
\text { jenis model promosi }\end{array}$ & $\begin{array}{l}\text { Bila sudah ada pelaku } \\
\text { yang menggunakan } \\
\text { lebih dari } 1 \text { media } \\
\text { promosi }\end{array}$ & $\begin{array}{l}\text { Bila penggunaan } \\
\text { berbagai model } \\
\text { promosi untuk } \\
\text { seluruh pelaku } \\
\text { telah dikoordinir }\end{array}$ & $\begin{array}{l}\text { Bila sudah } \\
\text { menggunakan } \\
\text { berbagai media } \\
\text { promosi dan } \\
\text { memanfaatkan } \\
\text { bebagai jaringan } \\
\text { komunikasi yang } \\
\text { terkoordinasi }\end{array}$ \\
\hline $\begin{array}{l}\text { C. Sistem } \\
\text { informasi } \\
\text { wisata }\end{array}$ & $\begin{array}{l}\text { Kombinasi dari teknologi } \\
\text { informasi dan aktivitas } \\
\text { orang yang } \\
\text { menggunakan teknologi } \\
\text { itu untuk mendukung } \\
\text { aktifitas wisata }\end{array}$ & $\begin{array}{l}\text { Bila belum } \\
\text { menggunakan } \\
\text { sistem informasi }\end{array}$ & $\begin{array}{l}\text { Bila sudah } \\
\text { menggunakan } 1 \\
\text { macam sistem } \\
\text { informasi oleh pelaku } \\
\text { wisata setempat }\end{array}$ & $\begin{array}{l}\text { Bila sudah } \\
\text { menggunakan aneka } \\
\text { macam sistem } \\
\text { informasi namun } \\
\text { digerakkan oleh pihak } \\
\text { luar }\end{array}$ & $\begin{array}{l}\text { Bila sudah } \\
\text { menggunakan } \\
\text { aneka bentuk } \\
\text { sisem informasi } \\
\text { wisata dan hanya } \\
\text { digerakkan oleh } \\
\text { pelaku wisata } \\
\text { setempat }\end{array}$ & $\begin{array}{l}\text { Bila sudah } \\
\text { menggunakan } \\
\text { aneka bentuk } \\
\text { sistem informasi } \\
\text { dan digerakkan } \\
\text { mandiri oleh pelaku } \\
\text { wisata setempat } \\
\text { dan aneka stake } \\
\text { holder }\end{array}$ \\
\hline $\begin{array}{l}\text { D. Distribusi } \\
\text { pemasaran }\end{array}$ & $\begin{array}{l}\text { Jangkauan relasi } \\
\text { pemasaran produk } \\
\text { wisata }\end{array}$ & $\begin{array}{l}\text { Bila jangkauan } \\
\text { relasi pemasaran } \\
\text { masih sangat lokal } \\
\text { (tingkat dalam } \\
\text { kabupaten dan } \\
\text { sekitarnya) }\end{array}$ & $\begin{array}{l}\text { Bila jangkauan relasi } \\
\text { pemasaran masih } \\
\text { lokal (tingkat antar } \\
\text { kabupaten dan } \\
\text { sekitarnya) }\end{array}$ & $\begin{array}{l}\text { Bila jangkauan relasi } \\
\text { pemasaran mencapai } \\
\text { propinsi- propinsi lain } \\
\text { yang ada di satu } \\
\text { pulau }\end{array}$ & $\begin{array}{l}\text { Bila jangkauan } \\
\text { relasi pemasaran } \\
\text { mencapai tingkat } \\
\text { nasional }\end{array}$ & $\begin{array}{l}\text { Bila jangkauan } \\
\text { relasi pemasaran } \\
\text { mencapai tingkat } \\
\text { internasional }\end{array}$ \\
\hline
\end{tabular}

\begin{tabular}{|c|c|c|c|c|c|c|}
\hline \multicolumn{7}{|c|}{ 2. KEBERLANJUTAN (SUSTAINABILITY) } \\
\hline \multirow{2}{*}{ PARAMETER } & \multirow{2}{*}{ RINCIAN UNSUR } & \multicolumn{5}{|c|}{ NILAI DAN INDIKATORNYA } \\
\hline & & Nilai 1 & Nilai 2 & Nilai 3 & Nilai 4 & Nilai 5 \\
\hline $\begin{array}{l}\text { A. Ambang batas } \\
\text { pembangunan fisik }\end{array}$ & $\begin{array}{l}\text { Penggunaan luas } \\
\text { lahan terbuka untuk } \\
\text { pembangunan fisik }\end{array}$ & $\begin{array}{l}\text { Bila masih belum } \\
\text { ada pengaturan } \\
\text { penggunaan lahan }\end{array}$ & $\begin{array}{l}\text { Bila sudah ada } \\
\text { pengaturan } \\
\text { penggunaan lahan } \\
\text { namun belum } \\
\text { dipatuhi }\end{array}$ & $\begin{array}{l}\text { Bila sudah ada } \\
\text { pengaturan dan } \\
\text { pembatasan } \\
\text { pembangunan fisik } \\
\text { dan mulai dipatuhi }\end{array}$ & $\begin{array}{l}\text { Bila sudah ada } \\
\text { pengaturan penggunaan } \\
\text { lahan dan } \\
\text { berkecenderungan } \\
\text { memperluas ruang } \\
\text { terbuka daripada } \\
\text { pembangunan fisik }\end{array}$ & $\begin{array}{l}\text { Bila sudah ada } \\
\text { pengaturan } \\
\text { penggunaan lahan } \\
\text { dan ada kepatuhan } \\
\text { serta kesediaan } \\
\text { revisi } \\
\text { pembangunan fisik }\end{array}$ \\
\hline $\begin{array}{l}\text { B. Ambang batas } \\
\text { jumlah pengunjung }\end{array}$ & $\begin{array}{l}\text { Jumlah pengunjung } \\
\text { di aneka obyek } \\
\text { wisata terhadap } \\
\text { daya dukung } \\
\text { lingkungan sesuai } \\
\text { standar UNWTO* }\end{array}$ & $\begin{array}{l}\text { Bila masih belum } \\
\text { ada skenario jalur } \\
\text { tapak dan } \\
\text { pengunjung hanya } \\
\text { mengerti titik daya } \\
\text { tarik tertentu }\end{array}$ & $\begin{array}{l}\text { Bila masih belum } \\
\text { ada skenario jalur } \\
\text { tapak untuk aliran } \\
\text { jumlah pengunjung } \\
\text { dan terjadi } \\
\text { penumpukan atau } \\
\text { sepi di titik-titik } \\
\text { tertentu }\end{array}$ & $\begin{array}{l}\text { Bila sudah ada jalur } \\
\text { tapak untuk aneka } \\
\text { titik daya tarik } \\
\text { namun belum ada } \\
\text { mekanisme } \\
\text { penyebaran jumlah } \\
\text { pengunjung }\end{array}$ & $\begin{array}{l}\text { Bila sudah ada jalur } \\
\text { tapak untuk aneka titik } \\
\text { daya tarik dan } \\
\text { mekanisme penyebaran } \\
\text { jumlah pengunjung }\end{array}$ & $\begin{array}{l}\text { Bila sudah ada jalur } \\
\text { tapak untuk aneka } \\
\text { titik daya tarik dan } \\
\text { jumlah pengunjung } \\
\text { tersebar sesuai } \\
\text { daya dukung tiap } \\
\text { obyek }\end{array}$ \\
\hline $\begin{array}{l}\text { C. Ambang batas } \\
\text { sumber daya alam }\end{array}$ & $\begin{array}{l}\text { Kemampuan suplai } \\
\text { dan daya tahan } \\
\text { sumber daya alam } \\
\text { atas kebutuhan } \\
\text { wisatawan di aneka } \\
\text { obyek wisata }\end{array}$ & $\begin{array}{l}\text { Bila masih belum } \\
\text { ada pengaturan } \\
\text { penggunaan } \\
\text { sumber daya alam } \\
\text { setempat }\end{array}$ & $\begin{array}{l}\text { Bila sudah ada } \\
\text { pengaturan } \\
\text { penggunaan } \\
\text { sumber daya alam } \\
\text { namun belum } \\
\text { dipatuhi }\end{array}$ & $\begin{array}{l}\text { Bila sudah ada } \\
\text { pengaturan dan } \\
\text { pembatasan } \\
\text { sumber daya alam } \\
\text { dan mulai dipatuhi }\end{array}$ & $\begin{array}{l}\text { Bila sudah ada } \\
\text { pengaturan penggunaan } \\
\text { sumber daya alam dan } \\
\text { berkecenderungan } \\
\text { memperbarui daya } \\
\text { dukung SDA }\end{array}$ & $\begin{array}{l}\text { Bila sudah ada } \\
\text { pengaturan } \\
\text { penggunaan } \\
\text { sumber daya alam } \\
\text { dan ada kepatuhan } \\
\text { serta kesediaan } \\
\text { berkontribusi bagi } \\
\text { pembaruan fungsi } \\
\text { SDA }\end{array}$ \\
\hline $\begin{array}{l}\text { D. Respon } \\
\text { masyarakat } \\
\text { setempat }\end{array}$ & $\begin{array}{l}\text { Reaksi dan aksi } \\
\text { masyarakat } \\
\text { setempat terhadap } \\
\text { aktifitas wisata di } \\
\text { wilayahnya }\end{array}$ & $\begin{array}{l}\text { Bila mayoritas } \\
\text { masyarakat tidak } \\
\text { meyukai ada } \\
\text { aktifitas wisata di } \\
\text { wilayahnya }\end{array}$ & $\begin{array}{l}\text { Bila mayoritas } \\
\text { masyarakat tidak } \\
\text { merasa perlu } \\
\text { terlibat atas } \\
\text { aktifitas wisata }\end{array}$ & $\begin{array}{l}\text { Bila mayoritas } \\
\text { masyarakat mau } \\
\text { terlibat aktifitas } \\
\text { pariwisata }\end{array}$ & $\begin{array}{l}\text { Bila masyarakat telah } \\
\text { membentuk organisasi } \\
\text { untuk mengatur peran } \\
\text { dalam aktifitas wisata }\end{array}$ & $\begin{array}{l}\text { Bila organisasi } \\
\text { pariwisata } \\
\text { bentukan } \\
\text { masyarakat telah } \\
\text { terkoneksi dengan } \\
\text { aneka stake holder }\end{array}$ \\
\hline $\begin{array}{l}\text { E. Respon } \\
\text { wisatawan }\end{array}$ & $\begin{array}{l}\text { Reaksi dan aksi } \\
\text { wisatwan yang } \\
\text { berkunjung }\end{array}$ & $\begin{array}{l}\text { Bila aneka obyek } \\
\text { wisata sepi dan } \\
\text { mangkrak }\end{array}$ & $\begin{array}{l}\text { Bila dikunjungi oleh } \\
\text { wisatawan individu } \\
\text { saja tidak ada grup } \\
\text { wisatawan }\end{array}$ & $\begin{array}{l}\text { Bila mulai } \\
\text { dikunjungi } \\
\text { wisatawan dalam } \\
\text { grup minimal } \\
\text { keluarga }\end{array}$ & $\begin{array}{l}\text { Bila mulai dipasarkan } \\
\text { oleh pelaku bisnis wisata }\end{array}$ & $\begin{array}{l}\text { Bila mulai menjadi } \\
\text { daftar kunjungan } \\
\text { penting bagi } \\
\text { wisatawan yang } \\
\text { datang ke destinasi }\end{array}$ \\
\hline $\begin{array}{l}\text { F. Respon } \\
\text { pemerintah }\end{array}$ & $\begin{array}{l}\text { Reaksi dan aksi } \\
\text { pemerintah atas } \\
\text { pengembangan } \\
\text { pariwisata di } \\
\text { wilayah tersebut }\end{array}$ & $\begin{array}{l}\text { Bila belum ada } \\
\text { respon pemerintah } \\
\text { dalam } \\
\text { perencanaan } \\
\text { wilayah tersebut }\end{array}$ & $\begin{array}{l}\text { Bila sudah masuk } \\
\text { dalam agenda } \\
\text { pengembangan } \\
\text { kawasan }\end{array}$ & $\begin{array}{l}\text { Bila sudah mulai } \\
\text { dimasukkan dalam } \\
\text { agenda } \\
\text { pengembangan } \\
\text { Pemda dan alokasi } \\
\text { anggaran }\end{array}$ & $\begin{array}{l}\text { Bila sudah melibatkan } \\
\text { berbagai stake holder } \\
\text { dalam pengembangan } \\
\text { wilayah }\end{array}$ & $\begin{array}{l}\text { Bila sudah } \\
\text { terkoneksi dalam } \\
\text { rencana } \\
\text { pemerintah propins } \\
\text { atau pusat dan } \\
\text { alokasi }\end{array}$ \\
\hline
\end{tabular}

MSP+DM (lihat Tabel 3). Tabel tersebut nantinya akan secara konsisten menjadi pegangan dalam mempersiapkan program pengembangan, memonitor proses dan progres pengembangan, serta mengevaluasi target yang dicapai dalam periode yang ditetapkan. Tabel yang telah dilengkapi dengan perincian unsur dan parameter nilai dapat dilihat pada tabel 2 di bawah ini: 


\begin{tabular}{|c|c|c|c|c|c|c|}
\hline & & & & & & anggarannya \\
\hline \multicolumn{7}{|c|}{ 3. PARTISIPASI (PARTICIPATORY) } \\
\hline \multirow{2}{*}{ PARAMETER } & \multirow{2}{*}{ RINCIAN UNSUR } & \multicolumn{5}{|c|}{ NILAI DAN INDIKATORNYA } \\
\hline & & Nilai 1 & Nilai 2 & Nilai 3 & Nilai 4 & Nilai 5 \\
\hline $\begin{array}{l}\text { A. Sumber daya } \\
\text { lokal (local } \\
\text { resources) }\end{array}$ & $\begin{array}{l}\text { Penggunaan aneka } \\
\text { sumber daya dan } \\
\text { bahan lokal di obyek } \\
\text { wisata }\end{array}$ & $\begin{array}{l}\text { Bila } \\
\text { masyarakat } \\
\text { pelaku tidak } \\
\text { mau } \\
\text { menggunakan } \\
\text { bahan lokal }\end{array}$ & $\begin{array}{l}\text { Bila pelaku } \\
\text { menggunakan sumber } \\
\text { daya lokal karena } \\
\text { keterpaksaan }\end{array}$ & $\begin{array}{l}\text { Bila pelaku mau } \\
\text { menggunaan sumber } \\
\text { daya lokal sebagai } \\
\text { pelengkap }\end{array}$ & $\begin{array}{l}\text { Bila mayoritas } \\
\text { pelaku } \\
\text { menggunakan } \\
\text { sumber daya lokal }\end{array}$ & $\begin{array}{l}\text { Bila pelaku telah } \\
\text { maksimal } \\
\text { menggunakan } \\
\text { sumber daya lokal } \\
\text { dan menjadikannya } \\
\text { sebagai sebuah } \\
\text { tema kawasan }\end{array}$ \\
\hline $\begin{array}{l}\text { B. Tanggung jawab } \\
\text { lokal (local } \\
\text { accountability) }\end{array}$ & $\begin{array}{l}\text { Keterlibatan } \\
\text { masyarakat lokal atas } \\
\text { pengelolaan dan } \\
\text { pengembangan } \\
\text { organisasi wisata } \\
\text { setempayy }\end{array}$ & $\begin{array}{l}\text { Bila } \\
\text { masyarakat } \\
\text { lokal tidak } \\
\text { mau terlibat } \\
\text { dalam aktifitas } \\
\text { wisata }\end{array}$ & $\begin{array}{l}\text { Bila masyarakat lokal } \\
\text { mau terlibat dalam } \\
\text { aktiftas parwisata namun } \\
\text { tidak ingin membentuk } \\
\text { organisasi }\end{array}$ & $\begin{array}{l}\text { Bila sudah ada } \\
\text { organisasi pariwisata } \\
\text { namun belum ada } \\
\text { aktifitas kegiatan }\end{array}$ & $\begin{array}{l}\text { Bila sudah ada } \\
\text { organisasi wisata } \\
\text { dan sebagai } \\
\text { regulator aktifitas } \\
\text { masyarakat } \\
\text { setempat }\end{array}$ & $\begin{array}{l}\text { Bila organisasi } \\
\text { wisata sudah terkait } \\
\text { dengan berbabagi } \\
\text { pemangku } \\
\text { kepentingan lintas } \\
\text { sektoral }\end{array}$ \\
\hline $\begin{array}{l}\text { C. Variasi daerah } \\
\text { setempat (local } \\
\text { variety) }\end{array}$ & $\begin{array}{l}\text { Keunikan aneka daya } \\
\text { tarik wisata setempat }\end{array}$ & $\begin{array}{l}\text { Bila tidak ada } \\
\text { keunikan } \\
\text { daerah } \\
\text { settempat } \\
\text { yang dikemas }\end{array}$ & $\begin{array}{l}\text { Bila sudah ada keunikan } \\
\text { daerah namun belum } \\
\text { dikemas }\end{array}$ & $\begin{array}{l}\text { Bila sudah ada } \\
\text { keunikan setempat } \\
\text { yang dikemas dalam } \\
\text { bentuk produk wisata }\end{array}$ & $\begin{array}{l}\text { Bila keunikan daya } \\
\text { tarik setempat } \\
\text { sudah menjadi } \\
\text { kesadaran kolektif } \\
\text { dan dikemas }\end{array}$ & $\begin{array}{l}\text { Bila keunikan daya } \\
\text { tarik setempat } \\
\text { sudah menjadi } \\
\text { kesadaran kolektif } \\
\text { dan dikemas serta } \\
\text { dilindungi } \\
\text { perangkat hukum }\end{array}$ \\
\hline $\begin{array}{l}\text { D. Keuntungan } \\
\text { ekonomi lokal }\end{array}$ & $\begin{array}{l}\text { Sebaran pendapatan } \\
\text { yang diterima oleh } \\
\text { masyarakat setempat } \\
\text { dan pelaku langsung }\end{array}$ & $\begin{array}{l}\text { Bila tidak ada } \\
\text { keuntungan } \\
\text { ekonomi yang } \\
\text { diterima } \\
\text { masyarakat } \\
\text { setempat }\end{array}$ & $\begin{array}{l}\text { Bila sudah ada sebagian } \\
\text { kecil anggota } \\
\text { masyarakat menerima } \\
\text { keuntungan ekonomi }\end{array}$ & $\begin{array}{l}\text { Bila sebagian besar } \\
\text { kebutuhan wisata } \\
\text { dapat dipenuhi oleh } \\
\text { aneka latar belakang } \\
\text { individu di masyarakat }\end{array}$ & $\begin{array}{l}\text { Bila sudah ada } \\
\text { lembaga usaha } \\
\text { yang dibentuk } \\
\text { untuk mengatur } \\
\text { pembagian } \\
\text { keuntutungan lebih } \\
\text { merata }\end{array}$ & $\begin{array}{l}\text { Bila lembaga usaha } \\
\text { yang dibentuk telah } \\
\text { terkait dengan } \\
\text { mayoritas warga } \\
\text { dan pihak eksternal }\end{array}$ \\
\hline \multicolumn{7}{|c|}{ 4. MITIGASI BENCANA (DISASTER MITIGATIOM) } \\
\hline \multirow{2}{*}{ PARAMETER } & \multirow{2}{*}{ RINCIAN UNSUR } & \multicolumn{5}{|c|}{ NILAI DAN INDIKATORNYA } \\
\hline & & Nilai 1 & Nilai 2 & Nilai 3 & Nilai 4 & Nilai 5 \\
\hline $\begin{array}{l}\text { A. Bencana alam } \\
\text { (misalnya gempa } \\
\text { bumi dan tanah } \\
\text { longsor) }\end{array}$ & $\begin{array}{l}\text { Antisipasi terhadap } \\
\text { resiko dan } \\
\text { perencanaan } \\
\text { pemulihan (recovery) }\end{array}$ & $\begin{array}{l}\text { Bila Belum ada } \\
\text { antisipasi dan } \\
\text { rencana } \\
\text { penyelamatan } \\
\text { bencana gempa } \\
\text { bumi dan tanah } \\
\text { longsor } \\
\end{array}$ & $\begin{array}{l}\text { Bila sudah ada } \\
\text { antisipasi dan rencana } \\
\text { penyelamatan } \\
\text { bencana gempa bumi } \\
\text { dan tanah longsor } \\
\text { namun belum } \\
\text { tersosialisasi }\end{array}$ & $\begin{array}{l}\text { Bila sudah ada } \\
\text { sosialiasi dan } \\
\text { pelatihan } \\
\text { penyelamatan }\end{array}$ & $\begin{array}{l}\text { Bila sudah ada jalur } \\
\text { penyelamatann dan } \\
\text { tim khusus yang } \\
\text { menangani } \\
\text { kebencanaan oleh } \\
\text { warga setempat }\end{array}$ & $\begin{array}{l}\text { Bila sudah ada } \\
\text { rencana dan } \\
\text { konsep wilayah } \\
\text { pemulihan pasca } \\
\text { bencana }\end{array}$ \\
\hline $\begin{array}{l}\text { B. Bencana non } \\
\text { alam akibat gagal } \\
\text { teknologi, wabah } \\
\text { penyakit (misalnya } \\
\text { kecelakaan mobl jip } \\
\text { wisata atau } \\
\text { keracunan } \\
\text { makanan) }\end{array}$ & $\begin{array}{l}\text { Antisipasi kesalahan } \\
\text { human eror dan } \\
\text { standarisasi minimal } \\
\text { keamanan dan } \\
\text { kesehatan }\end{array}$ & $\begin{array}{l}\text { Bila Belum ada } \\
\text { antisipasi dan } \\
\text { standarisasi } \\
\text { keamanan } \\
\text { minimal dan } \\
\text { kesehatan }\end{array}$ & $\begin{array}{l}\text { Bila Sudah ada } \\
\text { standarisasi minimal } \\
\text { namun belum } \\
\text { dijadikan acuan }\end{array}$ & $\begin{array}{l}\text { Bila sudah ada } \\
\text { standarisasi dan } \\
\text { menjadi acuan pelaku } \\
\text { wisata dan wisatawan }\end{array}$ & $\begin{array}{l}\text { Bila sudah ada } \\
\text { standarisasi } \\
\text { internasional } \\
\text { kemanan dan } \\
\text { kesehatan yang } \\
\text { ditaati }\end{array}$ & $\begin{array}{l}\text { Sudah ada } \\
\text { standarisasi } \\
\text { keamanan dan } \\
\text { kesehatan dan } \\
\text { ditegakannya } \\
\text { sanksi bagi yg } \\
\text { melanggar oleh } \\
\text { masyarakat } \\
\text { setempat } \\
\end{array}$ \\
\hline
\end{tabular}

Dari parameter dan penilaian yang digunakan untuk mengukur atraksi dan aneka potensi yang ada di kawasan pengembangan, maka diperoleh penilaian tentang kondisi awal

Tabel 3. Contoh Hasil Pengukuran Kondisi Kawasan Wisata Pantai XX

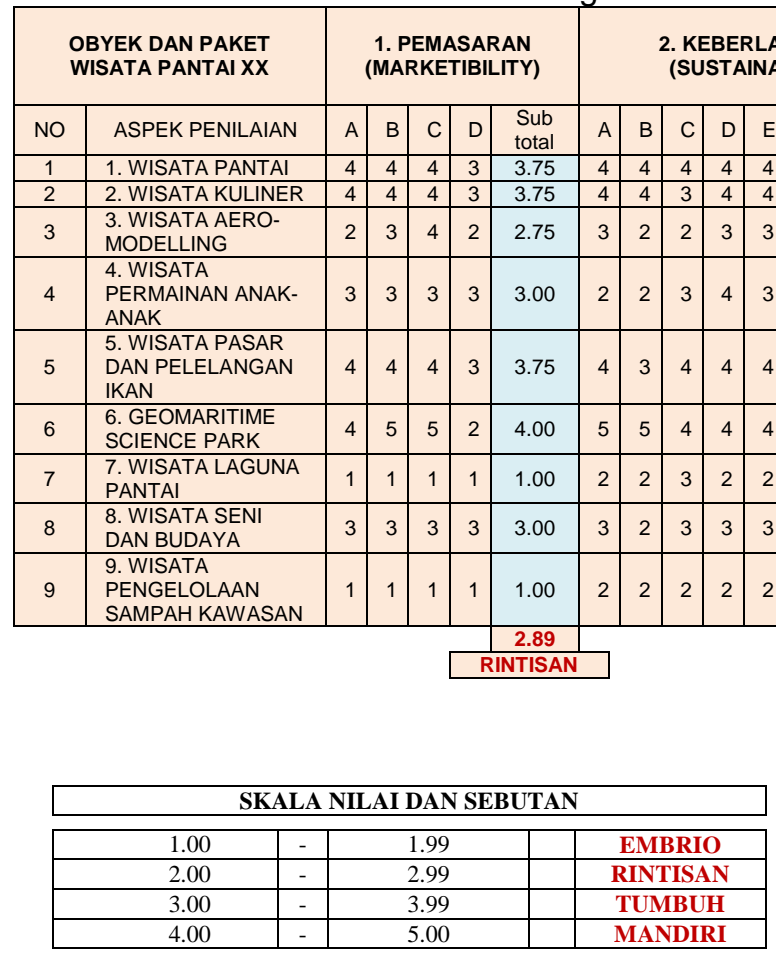


Pada contoh Tabel 4 di atas hasil analisa perhitungan dengan memandang variabel-variabel pada MSP+DM maka kawasan tersebut masuk dalam kategori Tumbuh. Oleh karena itu program pengembangan yang harus disiapkan adalah program yang bisa merubah dari indikator kriteria Tumbuh menjadi kriteria Mandiri. Untuk menentukan jenis program sesuai tingkatan kriteria maka digunakan kembali acuan skala yang sebelumnya pada Tabel 3. Dalam hal contoh ini, Pantai XX berada pada kriteria Tumbuh dengan kisaran nilai 3,00 sd 3,99 dan diharapkan menuju ke kriteria Mandiri pada kisaran nilai 4,00 sd 5,00 . Berdasarkan hal tersebut maka program yang dibuat harus mengacu dan menuju ke arah indikatorindikator pada kolom nilai 5 pada Tabel 3 .

\subsection{Simpulan Dan Saran}

\subsubsection{Simpulan}

Metode dalam penelitian ini menghasilkan kesimpulan sebagai berikut:

1. Untuk mengembangkan sebuah kawasan wisata analisis MSP+DM dapat menjawab tantangan jangka panjang (multi years) yang bersifat dinamis dibandingkan analisis SWOT yang bersifat kualitatif dan cenderung subyektif

2. Penggunaan analisis MSP+DM dapat mengurangi subyektifitas dalam menilai sebuah rencana pengembangan sekaligus evaluasi pada periode berjalan sebuah program pengembangan secara obyektif, terukur, dan konsisten

3. Program pengembangan kawasan nantinya ditepkan berdasarkan hasil analisis kondisi awal nilai MSP+DM sehingga strategi dan hasil yang diharapkan bisa terukur dan terevaluasi relatif mudah

\subsubsection{Saran}

1. Setiap rencana intervensi yang akan digunakan untuk alasan pengembangan kawasan pariwisata harus benar-benar terukur secara konsisten untuk menghindari munculnya keadaan dimana proyek yang tidak diterima masyarakat atau proyek tak terurus/mangkrak

2. Variabel-variabel dalam kepariwisataan harus benar-benar diperhatikan secara komprehensif dan obyektif sebelum memutuskan sebuah program pengembangan

\section{Daftar Pustaka}

[1] Arismayanti, N. K. (2010). Perencanaan dan Pengembangan Kawasan Pariwisata Di Bali. Jurnal Kepariwisataan Indonesia,
5(2), 195.

[2] ASEAN. (2015). ( ASEAN Tourism ). Retrieved April 20, 2017, from http://www.aseantourism.travel/blog/detail/ community-based-tourism-in-asean-region

[3] Gao, C. Y., \& Peng, D. H. (2011). Consolidating SWOT analysis with nonhomogeneous uncertain preference information. Knowledge-Based Systems, 24(6), 796-808. http://doi.org/10.1016/j.knosys.2011.03.00 1

[4] Garcia Lucchetti, V., \& Font, X. (2013). Community based tourism: critical success factors. ICRT Occasional Paper, (27), 1$21 . \quad$ Retrieved from http://www.icrtourism.org/wpcontent/uploads/2012/03/OP27.pdf

[5] Goranczewski, B., \& Puciato, D. (2010). SWOT Analysis in the Formulation of Tourism Development Strategies for Destinations. Tourism, 20(2). http://doi.org/10.2478/v10106-010-0008-7

[6] Huwae, K. C. (2008). Strategi Pemasaran Destinasi Pariwisata Pulau Ambon oleh Pelaku Bisnis Lokal. Gadjah Mada.

[7] Kotler, P., \& Amstrong, G. (2008). PrinsipPrinsip Pemasaran Jilid 1 (Principles of Marketing). (B. Sabran, Ed.) (12th ed.). Jakarta: Erlangga.

[8] Miller, H. E., Engemann, K. J., Yage, R. R., \& Yager, R. R. (2006). Communications of the IIMA Disaster Planning and Management Disaster Planning and Management. Communications of the IIMA, 6(2). Retrieved from http://scholarworks.lib.csusb.edu/cgi/viewc ontent.cgi?article $=1308 \&$ context $=$ ciima

[9] Oreski, D. (2012). Strategy development by using SWOT -AHP. TEM Journal, 1(4).

[10] Priatmoko, S. (2018). Analysis of Marketability, Sustainability, Participatory and Disaster Mitigation (MSP+DM) for the development of rural Community-Based Tourism (CBT) destinations Case study: Depok beach, Bantul, Yogyakarta. IOP Conference Series: Earth and Environmental Science, 202(1). http://doi.org/10.1088/17551315/202/1/012032

[11] Priatmoko, S. (2018). Working Rural Eco Tourism Planning in Yogyakarta Using MSP + DM Analysis. E-Journal of Tourism, $5(1)$, 22-29. http://doi.org/https://doi.org/10.24922/eot.v $5 i 1.38457$

[12] Purbadi, D. (2016). PENGEMBANGAN PROGRAM PEMBERDAYAAN MASYARAKAT BERKELANJUTAN STUDI 
KASUS: KAWASAN WISATA PANTAI BARU ,. In Seminar Nasional hasil Pengabdian masyarakat (SENDIMAS). Yogyakarta.

[13] Rangkuti, F. (2006). Analisis SWOT: Teknik Membedah Kasus Bisnis (14th ed.). Jakarta: Gramedia Pustaka Utama.

[14]Republik, I. UU 24 Tahun 2007 Tentang Penanggulangan Bencana (Disaster Management), Pub. L. No. UU 24 (2007). Indonesia.

[15]UNEP. (2011). Towards a Green Economy: Pathways to Sustainable Development and Poverty Eradication. Sustainable http://doi.org/10.1063/1.3159605

[16] UNISDR. (2009). Risk. 2009 UNISDR Terminology on Disaster Risk Reduction. Geneva: UNISDR.

[17] UNWTO. (2011). UNWTO Annual Report $A$ year of recovery.

[18] Zapata, M. J., Hall, C. M., Lindo, P., \& Vanderschaeghe, M. (2011). Can community-based tourism contribute to development and poverty alleviation? Lessons from Nicaragua. Current Issues in Tourism, 14(8), 725-749. http://doi.org/10.1080/13683500.2011.559 200 